\title{
Pesquisa de bioativos com atividade antimicrobiana nos extratos hidroetanólicos do fruto, folha e casca de caule do Zizyphus joazeiro mart
}

\author{
Maria do Socorro Fernandes MELO ${ }^{1}$, \\ Claudia Quintino da ROCHA ${ }^{2}$, \\ Marcelo Henrique dos SANTOS $^{3}$ \\ Juliana Moscardini CHAVASCO ${ }^{4}$ \\ Jorge Kleber CHAVASCO 5
} \author{
Farmacêutica Nacional, moscardiniju@gmail.com \\ Autor correspondente: \\ Prof. Dr. Jorge Kleber Chavasco \\ Departamento de Microbiologia e Imunologia \\ Universidade Federal de Alfenas-MG \\ 37130-000 - Alfenas - MG- Brasil \\ E-mail: jkchavasco@uol.com.br
}

${ }^{1}$ Universidade Federal de Alfenas-UNIFAL-MG. marisocmelo@hotmail.com

${ }^{2}$ Universidade Federal de Alfenas-UNIFAL-MG. claudiarocha3@yahoo.com.br

${ }^{3}$ Universidade Federal de Alfenas-UNIFAL-MG. marcelo.santos@unifal-mg.edu.br

${ }^{4}$ Farmacêutica, professora do curso de Farmácia da UNIVAS e Coordenadora do Controle de Qualidade da União Química

${ }^{5}$ Universidade Federal de Alfenas-UNIFAL-MG. jkchavasco@uol.com.br

Recebido em: 11/10/2012 - Aprovado em: 18/12/2012 - Disponibilizado em: 30/12/2012

\begin{abstract}
Resumo:
Zizyphus joazeiro Mart. árvore bastante disseminada no nordeste brasileiro, utilizada como agente de higienização bucal, em substituição aos produtos comerciais. Usa-se o fruto nas perturbações do estômago e as cascas na cicatrização de ferimentos, febres e infecções dos pulmões. O presente estudo objetiva avaliar a atividade antimicrobiana, in vitro dos diferentes extratos de Zizyphus joazeiro Mart frente á microrganismos, incluindo leveduras, bactérias Grampositiva, Gram-negativa e Mycobacterium bovis. Os extratos foram preparados utilizando as partes aéreas (casca do caule, folhas e frutos) de Zizyphus joazeiro Mart. Esses foram testados quanto a sua atividade antimicrobiana, contra leveduras e bactérias utilizando o método de difusão em agar. Todos os extratos apresentaram atividade antimicrobiana. Dos microrganismos utilizados somente Bacillus subtilis, Staphylococcus aureus e Candida albicans mostraram-se sensíveis. Nenhum dos extratos testados apresentou atividade sobre Mycobacterium bovis. Estes resultados podem explicar em parte a utilização Zizyphus joazeiro Mart. para o tratamento de doenças infecciosas na medicina tradicional. Palavras-chave: Zizyphus joazeiro. Extratos vegetais. Antimicrobiana. Antimicobacteriana. M.bovis
\end{abstract}

\section{Research with antimicrobial activity of bioactive hydroethanolic extracts fruit, leaf and stem bark of Zizyphus joazeiro mart}

\begin{abstract}
:
Zizyphus joazeiro Mart. Tree fairly widespread in northeastern Brazil, used as oral hygiene agent, to replace commercial products. It is used in the fruit disorders of the stomach and the shells in wound healing, fevers and infections of the lungs. The present study aims to evaluate the antimicrobial activity in vitro of different extracts of Zizyphus joazeiro Mart opposite the microorganisms, including yeasts, Gram-positive, Gram-negative and Mycobacterium bovis. The extracts were prepared using the aerial parts (stem bark, leaves and fruits) of Zizyphus joazeiro Mart. These were tested for their antimicrobial activity against yeasts and bacteria using the agar diffusion method. All extracts showed antimicrobial activity. The microorganisms used only Bacillus subtilis, Staphylococcus aureus and Candida albicans were susceptible. None of the tested extracts showed activity on Mycobacterium bovis. These results may partly explain the use Zizyphus joazeiro Mart. for the treatment of infectious diseases in traditional medicine.
\end{abstract}

Keywords: Zizyphus joazeiro Mart. Plant extracts, Antimicrobial. Antimycobacterial. M bovis 


\section{Introdução}

Na America do Sul, são encontradas varias espécies do gênero Zizyphus entre elas Zizyphus joazeiro Mart que cresce em áreas de caatinga do Brasil. Zizyphus joazeiro Mart. é largamente distribuída em todo o Nordeste brasileiro e em zonas ecológicas, sendo mais abundante no sertão, na caatinga e no agreste ( SILVA e MATOS, 1998). Utilizada como agente de higienização bucal, em substituição aos produtos comerciais, suas folhas e fragmentos de casca do caule são mastigados ou friccionados contra os dentes, essa operação produz abundante quantidade de espuma, devido ao elevado teor de saponinas presente nessa espécie (CRUZ, 1979). Conserva-se verde durante todo o ano e nunca perde toda a folhagem; as folhas e os frutos constituem um dos mais valiosos recursos alimentares para animais, nos períodos de seca (LORENZI e MATOS, 2002). A infusão das folhas é popularmente utilizada como digestivo e as raspas da entrecasca são ricas em saponina, servindo de sabão, dentifrício e um excelente tônico capilar; a madeira é boa para mourões de cerca e para marcenaria (SILVA e MATOS, 1998).

$\mathrm{Na}$ medicina herbária brasileira, o decocto do caule, é utilizado contra bronquite crônica, infecções no trato respiratório superior e urogenital, dores de garganta, febres (NUNES et al.,1987) e placas dentárias, no tratamento de úlceras.como expectorante fluidifica as secreções brônquicas facilitando a expectoração (BRAGA, 1976). Externamente, a tintura é usada em loções capilares. Em doses elevadas produz vômitos, cólicas e forte irritação do tubo gastrointestinal. As formas farmacêuticas habituais são Infuso, decocto, extrato fluido, tintura, poções entre outras (COIMBRA, 1958).

O presente estudo teve como objetivo avaliar in vitro a atividade antimicrobiana dos diferentes extratos de Zizyphus joazeiro Mart frente á microrganismos, incluindo leveduras, bactérias Gram-positiva, Gram-negativa e Mycobacterium tuberculosis, utilizando o teste de difusão em agar para que no futuro esta pesquisa contribua para a utilização terapêutica desta planta nos processos infecciosos.

\section{Materiais e métodos}

\subsection{O material vegetal}

As folhas, frutos e casca do caule de Zizyphus joazeiro Mart foram coletados em abril de 2008, no município de Pombos, Zona da Mata Sul, em Pernambuco-Brasil, identificado no Herbário Sergio Tavares do Departamento de Ciências Florestais da Universidade Federal Rural de Pernambuco e depositado neste sob o registro $\mathrm{n}^{\mathrm{o}} 15638$.

\subsection{Obtenção dos extratos}

As partes aéreas (casca do caule, folhas e frutos) de Zizyphus joazeiro Mart foram trituradas em liquidificador domestico 
na proporção de $200 \mathrm{~g}$ para $800 \mathrm{~mL}$ de etanol a $70 \%$ e deixados macerar por 7 dias ao abrigo da luz com uma agitação diária. Os extratos foram filtrados e concentrados em evaporador rotatório a temperatura de $60^{\circ} \mathrm{C} \mathrm{e}$ pressão negativa de 400 a $500 \mathrm{mmHg}$. Após a concentração, alíquotas de $20 \mathrm{~mL}$ de cada extrato foram liofilizadas e determinadas o peso seco de cada alíquota. Para as análises, os mesmos foram ressuspensos em água destilada estéril na concentração de 100 $\mathrm{mg} / \mathrm{mL}$ e esterilizados por filtração em filtro Millipore de 0,45 $\mu \mathrm{mL}$. (SILVA et al, 2010)

\subsection{Triagem fitoquímica qualitativa}

Os extratos hidroalcoólico da casca do caule, folhas e frutos (verdes e maduros) de Zizyphus joazeiro Mart foram submetidos a uma investigação dos constituintes químicos por classe metabólica. As classes de metabólitos secundários (saponinas, alcalóides, taninos, flavonóides, esteróides e triterpenos) foram realizados em triplicata $\mathrm{e}$ de acordo com Matos (2008), constantes do Quadro 01.

\subsection{Atividade antimicrobiana}

\subsubsection{Microrganismos}

Foram utilizadas as seguintes amostras microbianas: Staphylococcus aureus (ATCC 6538) Escherichia coli (ATCC 8739); Pseudomonas aeruginosa (ATCC 9027); Salmonella typhi (ATCC 14028); Proteus mirabilis ( ATCC 25922); Micrococcus luteus (ATCC 9341), Bacillus cereus (ATCC 11778); Bacillus subtilis (ATCC 6633);
Candida albicans (ATCC 10231), Saccharomyces cerevisae (ATCC 2601) e Mycobacterium bovis (amostra BCG), mantidas no Laboratório de Microbiologia e Imunologia Básicas da UNIFAL-MG.

\subsubsection{Meios de cultura}

O Meio Lowenstein-Jensen foi utilizado para cultivo do Mycobacterium bovis. Foram utilizados Agar Mueller-Hinton para as bactérias e Mueller-Hinton com glicose para leveduras. O caldo Mueller Hinton e caldo Mueller Hinton com glicose foram usado para a determinação da concentração mínima inibitória (CIM).

\subsubsection{Determinação atividade antimicrobiana}

Para a avaliação da atividade antimicrobiana dos extratos hidroetanólicos foi utilizado o método de difusão em agar que é atualmente recomendado pelo CLSI (Clinical and Laboratory Standards Institute, 2003) com modificações e que se baseia no método descrito por Bauer et al. (1966). As cepas bacterianas foram repicadas em agar Mueller-Hinton e as de leveduras em agar Mueller-Hinton com glicose e incubadas à $37^{\circ} \mathrm{C}, 24$ horas antes do teste. Para o preparo do inóculo, as culturas foram padronizadas em solução salina estéril segundo a escala 0,5 de MacFarland. Os extratos das partes aéreas (folhas, frutos verde, fruto maduro e casca do caule) de Zizyphus joazeiro Martius foram diluídos a uma concentração de $100 \mathrm{mg} / \mathrm{mL}$. Foram perfurados poços com $4 \mathrm{~mm}$ de diâmetro na superfície do meio de cultura e 
posteriormente inoculados com a suspensão microbiana padronizada. Cada extrato foi colocado nos poços num volume de 40 microlitros juntamente com o controle positivo ( clorexidina a $0,12 \%$ ) e controle negativo ( água destilada). As placas foram incubadas a $37^{\circ} \mathrm{C}$ por 24 horas. Após a incubação foi feita a leitura dos halos de inibição do crescimento microbiano em volta dos poços.

$$
\text { Para a avaliação da atividade }
$$
antimicrobiana dos extratos hidroetanólico frente ao Mycobacterium bovis foi empregado o método da difusão baseado na técnica anterior utilizando o meio de Lowenstein-Jensen acondicionado em garrafas plásticas para cultura de células nos quais foram colocados os discos teste impregnados com os extratos na superfície. As garrafas com Meio de Lowenstein-Jensen inoculadas com Mycobacterium bovis foram incubadas $37^{\circ} \mathrm{C}$ por quatro semanas. No final foram avaliados os halos de inibição formados ao redor dos discos. Estes testes foram feitos em triplicata com soluções controle, ou seja, solução de rifamicina a 50 $\mu$ e água destilada.

A concentração inibitória mínima foi determinado nos extratos que apresentaram atividade inibitória no teste de difusão em agar. Os testes foram realizados em microplacas nas quais foram colocados 100 $\mu \mathrm{L}$ do caldo Mueller Hinton concentrado $2 \mathrm{x}$ no primeiro poço e com concentração normal nos demais. Concentrações decrescentes do extrato foram colocados nos poços a partir de $50 \mathrm{mg} / \mathrm{mL}$ ate $0,39 \mathrm{mg} / \mathrm{mL}$. Foram inoculados nos poços $10 \mu \mathrm{L}$ da suspensão microbiana com turvação equivalente ao tubo $0,5 \mathrm{da}$ Escala de Mac Farland. As placas foram incubadas a $37^{\circ} \mathrm{C}$ por 24 horas. A leitura foi feita a partir do ultimo tubo onde não houve turvação ou seja a menor concentração que inibiu o crescimento microbiano. Os resultados são apresentados no Quadro 02.

\section{Resultados}

\subsection{Triagem fitoquímica qualitativa}

Os resultados obtidos na prospecção fitoquímica dos quatro extratos utilizadas neste estudo, estão representados na Tabela 01. Na análise fitoquímica da casca do caule de Zizyphus joazeiro Mart. constatou-se a presença de saponinas, esteróide e triterpenos. A presença de saponina, esteróide e triterpenos também foram observadas nas folhas e frutos maduros. O resultado foi positivo para presença de alcalóides nas folhas. Foi verificada a presença de alcalóides nos frutos maduros de Zizyphus joazeiro. Observou-se a presença de flavonóides nos frutos. Os taninos foram detectados nas folhas e frutos verdes. 
Quadro 01- Prospecção fitoquímica realizada nos extratos hidroalcoólicos de casca do caule, folhas, fruto verde, em maturação e maduro de Zizyphus joazeiro Mart

\begin{tabular}{lccccc}
\hline $\begin{array}{l}\text { Metabolitos/ } \\
\text { Amostras }\end{array}$ & Alcalóides & Saponinas & Flavanóides & $\begin{array}{c}\text { Esteróídes } \\
\text { Triterpenos }\end{array}$ & Taninos \\
\hline Casca do caule & - & + & - & + & - \\
Folhas & + & + & - & + & + \\
Fruto verde & - & - & + & + & + \\
Fruto maduro & + & + & + & + & + \\
\hline
\end{tabular}

Fonte: $\mathrm{O}$ autor $\quad$ (-) reação negativa. (+) reação positiva.

Quadro 02- Avaliação da atividade antimicrobiana de extratos hidroalcoólico de Zizyphus joazeiro. (diâmetro dos halos de inibição expressos em mm)

\begin{tabular}{|l|c|c|c|c|c|c|c|}
\hline $\begin{array}{l}\text { EXTRATOS/ } \\
\text { MICROGANISMOS }\end{array}$ & $\begin{array}{c}\text { Casca do } \\
\text { caule }\end{array}$ & Folhas & $\begin{array}{c}\text { Frutos } \\
\text { verdes }\end{array}$ & $\begin{array}{c}\text { Frutos } \\
\text { maduro }\end{array}$ & $\begin{array}{c}\text { Clorexidina } \\
0,12 \%\end{array}$ & $\begin{array}{c}\text { Sol. de } \\
\text { Rifamicina } \\
\text { Agua }\end{array}$ & $\begin{array}{c}\text { Agstilada } \\
\text { des }\end{array}$ \\
\hline $\begin{array}{l}\text { Bacillus cereus } \\
\text { ATCC 11778 }\end{array}$ & 0 & 0 & 0 & 0 & 12 & NT & 0 \\
\hline $\begin{array}{l}\text { Bacillus subtilis } \\
\text { ATCC 6633 }\end{array}$ & 12 & 7 & 0 & 6 & 15 & NT & 0 \\
\hline $\begin{array}{l}\text { Escherichia coli } \\
\text { ATCC 25922 }\end{array}$ & 0 & 0 & 0 & 0 & 13 & NT & 0 \\
\hline $\begin{array}{l}\text { Micrococcus luteus } \\
\text { ATCC 9341 }\end{array}$ & 0 & 0 & 0 & 0 & 21 & NT & 0 \\
\hline $\begin{array}{l}\text { Proteus mirabilis } \\
\text { ATCC 25933 }\end{array}$ & 0 & 0 & 0 & 0 & 9 & NT & 0 \\
\hline $\begin{array}{l}\text { Pseudomonas aeruginosa } \\
\text { ATCC 27853 }\end{array}$ & 12 & 0 & 0 & 0 & 14 & NT & 0 \\
\hline $\begin{array}{l}\text { Salmonella typhi } \\
\text { ATCC 14028 }\end{array}$ & 0 & 0 & 0 & 0 & 10 & NT & 0 \\
\hline $\begin{array}{l}\text { Staphylococcus aureus } \\
\text { ATCC 6538 }\end{array}$ & 0 & 0 & 8 & 0 & 16 & NT & 0 \\
\hline $\begin{array}{l}\text { Candida albicans } \\
\text { ATCC 10231 }\end{array}$ & 10 & 0 & 0 & 0 & 15 & NT & 0 \\
\hline $\begin{array}{l}\text { Sacharomyces cerevisae } \\
\text { ATCC 2601 }\end{array}$ & 0 & 0 & 0 & 0 & 18 & NT \\
\hline $\begin{array}{l}\text { Mycobacterium bovis } \\
\text { Amostra BCG) }\end{array}$ & 0 & 0 & 0 & 0 & NT & 22 \\
\hline Fonte: O aut & & 0 & 0 & 0 \\
\hline
\end{tabular}

Fonte: $\mathrm{O}$ autor - NT = Não Testado

\subsection{Atividade antibacteriana}

Os diferentes extratos de hidroetanólico de Zizyphus joazeiro utilizados não demonstraram eficácia sobre os seguintes microrganismos: Micrococcus luteus, Proteus mirabilis,, Salmonella typhi e Saccharomyces cerevisiae. Todas as partes da planta exibiram atividade antimicrobiana contra algumas das cepas testadas. A parte da planta com as maior atividade antimicrobiana foi à casca do caule com atividade frente à Bacillus subtilis, Candida albicans e Pseudomonas aeruginosa apresentando halos de inibição do crescimento de 12,10 e $12 \mathrm{~mm}$ de diâmetro 
respectivamente confirmando o resultado obtido por Cruz et al., (2007). O extrato de folhas apresentou resultado positivo apenas para Bacillus subtilis (ATCC 6633) cujo halo de inibição foi de $7 \mathrm{~mm}$.

O extrato de fruto verde foi efetivo apenas para o Staphylococcus aureus (ATCC 6538) enquanto que o extrato de fruto maduro apresentou atividade inibitória contra Bacillus subtilis (ATCC 6633) apresentando halo de 6 mm. Nenhum dos extratos utilizados demonstrou atividade contra o Mycobacterium bovis.

Em relação à avaliação da concentração inibitória mínima (CIM), foram utilizados apenas os microrganismos que inicialmente mostraram-se sensíveis aos extratos, ou seja: Bacillus subtilis, Staphylococcus aureus, Candida albicans $e$ Pseudomonas aeruginosa (Tabela 2). Na determinação da concentração inibitória mínima apenas o extrato da casca do caule apresentou atividade antimicrobiana, sendo esta limitada ao Bacillus subtilis cuja a CIM foi de $40 \mathrm{mg} / \mathrm{mL}$.

\section{Discussão}

$\mathrm{Na}$ análise fitoquímica a presença de saponina, esteróides e triterpenos observadas nas folhas, frutos maduros e casca do caule de Zizyphus joazeiro Mart confirmam resultados encontrados por Silva (2008) e Braga (1976) estes compostos podem atuar na maximização do potencial da referida espécie para sanar gastrites e ferimentos, por outro lado atribuise a ação a antifúngica, antibacteriana ás saponinas (TAIZ e ZEIGER, 1991). A atividade inibitória dos três extratos frente ao Bacillus subtilis pode ser atribuída, possivelmente em combinação, entre os três fitoquímicos.

Os taninos foram detectados nas folhas e frutos verdes. Sanches et al., (2005) relatam que taninos têm efeito inibitório sobre bactérias e fungos. Existem três hipóteses para o mecanismo de ação antimicrobiana. A primeira hipótese pressupõe a inibição das enzimas de bactérias e fungos e/ou a complexação dos substratos dessas enzimas; a segunda seria a ação dos taninos sobre as membranas celulares dos microrganismos, modificando o seu metabolismo (MELLO e SANTOS, 2002). Finalmente, a terceira hipótese menciona a complexação dos taninos com íons metálicos, diminuindo, assim, a disponibilidade destes elementos essenciais para o metabolismo dos microrganismos. Os resultados das análises fitoquímicas feitas por Sousa (2007) registraram a presença de saponinas, taninos, flavonóides, catequinas e xantonas. $\mathrm{O}$ resultado positivo para alcalóides nas folhas diferem de resultados obtidos por Silva, (2008) e quanto a presença de alcalóides nos frutos maduro de Zizyphus joazeiro não há relato na literatura para comparação. A presença de flavonóide nos frutos maduros confirma resultados também 
obtidos por outros pesquisadores em diferentes espécies Zizyphus (Zizyphus spinachristi e Zizyphus jujuba Miller) (PAWLOWSKA et al.,2009).

$\mathrm{Na}$ triagem antimicrobiana das partes aéreas dos extratos hidroetanólicos de Zizyphus joazeiro Mart todos os extratos apresentaram atividade antimicrobiana frente a pelo menos um microrganismos testados e dos microrganismos utilizados somente Bacillus subtilis, Staphylococcus aureus e Candida albicans mostraram-se sensíveis.

Os extratos de plantas são geralmente uma mistura de compostos ativos e inativos e suas atividades antimicrobianas devem ser interpretados com critérios (GUERRA e NORDARI, 2004).

Cruz et al. (2007) realizaram estudos da atividade antifúngica do extrato de folhas e entrecasca do caule de Zizyphus joazeiro. Esses extratos apresentaram efetividade contra seguintes fungos: Candida albicans, Candida guilliermondii, Cryptococcus neoformans, Trichophyton rubrum e Fonsecaea pedrosoi. Lima (2008) estudou a ação antifúngica e antibacteriana do extrato aquoso, hidroalcoólico, etanólico e hexânico das folhas de Zizyphus joazeiro. O extrato hexânico e extrato etanólico obtiveram desempenho superior ao aquoso, foi encontrado efetividade significativa contra Bacillus subtilis, Enterobacter aerogenes, Escherichia coli, Klebsiella pneumoniae Pseudomonas aeruginosa, Salmonella choleraesuis, Staphylococcus aureus. O extrato aquoso de folhas Ziziphus joazeiro testado por Lima, (2008) não inibiu o crescimento dos microrganismos utilizados. Vários fatores podem interferir na atividade biológica de extratos vegetais principalmente o local e o período da coleta e tipos de solventes utilizados para a extração. A polaridade de substâncias antimicrobianas segundo Silva (2008) é um fator importante, especialmente quando se avalia substâncias apolares pelo método de difusão em agar. Extratos mais apolares apresentam maior atividade contra um numero maior de microrganismos. Desta forma, pesquisas de frações bioativas com atividade antimicrobiana deverão ser realizadas em Zizyphus joazeiro. Na literatura não há relato para comparação de resultados de atividade antimicrobiana para extratos de frutos, somente para casca de caule e folhas. Nenhum dos extratos utilizados demonstrou atividade contra o Mycobacterium bovis.

Em relação à avaliação da concentração inibitória mínima (CIM), apenas o extrato da casca do caule apresentou atividade antimicrobiana, sendo esta limitada ao Bacillus subtilis cuja a CIM foi de 40 $\mathrm{mg} / \mathrm{mL}$. Valores de CIM iguais ou menores que $1 \mathrm{mg} / \mathrm{mL}$ para o extrato bruto ou frações e valores de CIM iguais ou menores que 0,25 $\mathrm{mg} / \mathrm{mL}$ para as substancias puras foram os critérios usados por Campos (2006) para determinar a atividade da substância ou seja 
substancias com valores acima destes não tem potencias para uso como antimicrobiano. Neste trabalho a CIM foi igual a $40 \mathrm{mg} / \mathrm{mL}$, valores estes muito acima do preconizado pela literatura. Concentrações altas inviabilizam a utilização do produto, pois aumentam consideravelmente sua toxicidade. Numa discussão sobre as propriedades antifúngica de extratos de plantas medicinais Carmeli et al., (1999), em estudos com Candida albicans ATCC 90028, encontrou valores de 0,80 mg / $\mathrm{ml}$ que foram interpretados como forte atividade antifúngica.Os autores observaram que MICs/ $\mathrm{ml}$ menores que 1,00 mg deve ser interpretado como forte potencial antifúngico.

Os outros extratos não foram efetivos talvez pela impossibilidade de se usar concentrações maiores. A alta viscosidade inviabiliza a filtração para esterilização do mesmo. Testes posteriores poderão ser aplicados utilizando a técnica de radiação gama para esterilização de soluções concentradas. Estudo das plantas medicinais, quanto aos seus aspectos fitoquímicos, fornece informações úteis, possibilitando a identificação de compostos ativos e sua localização no vegetal. Estas informações são essenciais para indicar a melhor parte do vegetal a ser utilizada para a obtenção de compostos de interesse medicinal, informando a população acerca da utilização racional de um bem natural, minimizando o número de coletas e direcionando para uma coleta menos predatória, que pode levar a espécie à extinção.

\section{5- Conclusão}

Os resultados nos permite concluir que os extratos hidroetanólicos de Zizyphus joazeiro possuem atividade antimicrobiana.

Os extratos da casca do caule foram os mais efetivos atuando em um numero maior de microrganismos.

B. subtilis foi o microrganismo mais sensível à ação dos extratos.

\section{6-Agradecimentos}

Este trabalho teve o apoio FAPEMIG, CNPq, CAPES e UNIFAL-MG.

\section{7- Referencias Bibliográficas}

1- BAUER, A. W. et al., 1966. Antibiotic susceptibility testing by a standardized single disc method. American Journal of Clinical Pathology 45, 493-496.

2- BRAGA, R.. Plantas do Nordeste, especialmente do Ceará. Mossoró:Editora Universitária da UFRN , 1976

3- CAMPOS, M. P.,2006. "Analise do potencias antimicrobiano do extrato, fraçõese substâncias puras obtidas de Piper solmsianum" (Dissertação) - Mestrado, Universidade Vale do Itajai,Itajaí-SC,2006.

4- CARMELI, Y., TROILLET, N., ELIOPOULOS, G.M., SAMORE, M.H., 1999. Emergence of Antibiotic-resistant Pseudomonas aeruginosa: comparison of 
risks associated with different antipseudomonal agents. Antimicrobial Agents and Chemotherapy 43, 1379-1382.

5- Clinical and Laboratory Standards Institute (CLSI) 2003. Methods for dilution antimicrobial susceptibility tests for bacteria that grow aerobically. Approved standard Sixth edition. M7-A6. Wayne, PA, USA: CLSI.

6- COIMBRA, R. 1958. Notas de fitoterapia. Rio de Janeiro: Laboratório Clínico Silva Araújo, 429p.

7- CRUZ, G. L., 1979. Dicionário das plantas úteis do Brasil. Rio de Janeiro:

Civilização Brasileira, 559 p.

8- CRUZ, M.C.S. et al., 2007. Antifungal activity of Brazilian medicinal plants involved in popular treatment of mycoses. Journal of Ethnopharmacology 111, 409-410.

9- GUERRA, R.O. ; NODARI, M. P., 2004. Biodiversidade: aspectos biológicos, geográficos, legais e éticos. In: SIMÕES, C. M. O. et al. (Org.). Farmacognosia: da planta ao medicamento. 5. ed. Porto Alegre: Editora da UFRGS, pp. $13-28$.

10- LIMA, P. M., 2008. Avaliação da atividade de extratos de folhas de Momordica charantia, Auxemma oncocalyx e Ziziphus joazeiro sobre bactérias e larvas de Culex quinquefasciatus. Dissertação (Mestrado)Universidade Federal Rural do Semi-Árido, Mossoró.

11- LORENZI, H.; MATOS, F. J. A.,2002. Plantas medicinais no Brasil: nativas e exóticas. Nova Odessa - SP: Ed. Plantarum, 238-241.

12-MATOS, F. J. A. ,2008. Introdução à fitoquímica experimental. Fortaleza, Ceara : Ed. da Universidade Federal do Ceara, 148.

13- MELLO, C. P.; SANTOS, S. C.2002. Taninos. In: Farmacognosia: da planta ao medicamento. Organizadopor Cláudia Maria
Oliveira Simões et al. 4 ed. Porto Alegre / Florianópolis: Editora Universitária / UFRGS /Ed. da UFSC, pp. 950

14- NUNES, PH, et al. 1987."A atividade antipirético de um extrato aquoso de Zizyphus joazeiro Mart. (Rhamnaceae)." J. Med. Biol.20, 599-601.

15- PAWLOWSKA A.M. et al.,2009. Flavonoids of Zizyphus jujuba L. and Zizyphus spina-christi (L.)

Willd.(Rhamnaceae) fruits Food Chemistry $112,858-862$

16- SILVA, L. M. M.; MATOS, V. P. 1998. Morfologia de frutos, sementes e plântulas de catingueira (Caesalpinia pyramidalis Tul. Caesalpinaceae) e de juazeiro (Zizyphus joazeiro Mart. -Rhamnaceae). Revista Brasileira de Sementes, Brasília 20, 263-269.

17- SILVA, M. D. ,2008. Estudo farmacobotânico de três espécies medicinais da caatinga em Pernambuco. Dissertação (Mestrado em Botânica) - Universidade Federal Rural de Pernambuco, Recife.

18-SILVA, R. B., ALMEIDA,C. R. CHAVASCO,J.M.; CHAVASCO,J.K 2010. Antimicobacterial Activity Evaluation and MIC Determination of Bixa Orellana L Liophilizated Hydroalcoholic Extracts.Revista Brasileira de Farmacognosia 20(2):171-174.

19- SOUSA, T. S., 2007. Análise fitoquímica e ação antioxidante de zizyphus joazeiro $\mathrm{e}$ zizyphus undulata. IN: SEMANA UNIVERSITÁRIA, $7^{\circ}$ ENCONTRO DE INICIAÇÃO CIENTÍFICA CIENCIAS EXATAS E DA TERRA, Fortaleza. Livro de Resumo, Fortaleza: Universidade Federal do Ceará, 2007.

20- TAIZ L.; ZEIGER E. (Ed.). 1991. Surface protection and secondary metabolites defense compounds. In: TAIZ, L.; ZEIGER, E. (Ed.). Plant Physiology. Califórnia: Cummins Company, 318-345. 